\title{
Is There True Gender Difference of Irritable Bowel Syndrome in Asia?: Author's Reply
}

\author{
Govind K Makharia \\ Department of Gastroenterology and Human Nutrition, All India Institute of Medical Sciences, New Delhi, India
}

TO THE EDITOR: We appreciate sincerely the interest of Dr. Jung on our paper on the "Prevalence of irritable bowel syndrome: a community based study from Northern India". ${ }^{1}$ We do agree with the points raised by Dr. Jung.

We limited the age group of participants between 18-64 years in this study. In elderly, the clinical features of colonic malignancy may mimic that of irritable bowel syndrome (IBS) and before making a diagnosis of IBS, one needs to do thorough investigations to exclude organic diseases including colon cancer especially once the symptoms are of recent origin.

IBS is more common in women than in men in many Western countries. No consistent gender difference however has been observed in the community based studies from Asia. ${ }^{2}$ A clear male predominance is observed in patients with IBS in hospital based studies. In male dominant society, health seeking behavior of males is probably the best explanation for a difference in the prevalence of IBS in the studies conducted in hospital setting and those done in the community.

We agree with Dr. Jung that more information should be drawn in any epidemiological study. Since we had piggy bagged this study with our main objective of finding out the community prevalence of celiac disease, we purposely kept the questionnaire related with IBS to the basic minimum. ${ }^{3}$

We thank again Dr. Jung for bringing some of her thoughts on our paper.

Govind K Makharia

Department of Gastroenterology and Human Nutrition All India Institute of Medical Sciences New Delhi, India

1. Makharia GK, Verma AK, Amarchand R, et al. Prevalence of irritable bowel syndrome: a community based study from Northern India. J Neurogastroenterol Motil 2011;17:82-87.

2. Chang FY, Lu CL, Chen TS. The current prevalence of irritable bowel syndrome in Asia. J Neurogastroenterol Motil 2010;16:389400.

3. Makharia GK, Verma AK, Amarchand R, et al. Prevalence of celiac disease in the Northern part of India: a community based study. J Gastroenterol Hepatol Published Online First: 23 Dec 2010. doi: $10.1111 / \mathrm{j} .1440-1746.2010 .06606 . x$

\section{Conflicts of interest: None.}

